\title{
The Conceptual Framework of Business Process Management
}

\author{
Gunyung Lee \\ Professor, Faculty of Economics, Niigata University
}

\section{Introduction}

It is generally known that today's era - the IT era - is characterized by the global spread of information networks using Information Technology and the Internet in the IT era, corporate activities both inside and outside the corporation, are conducted in multiple areas simultaneously and surpass the hitherto existing limits of time and space. Because of this historical background and the complete environmental change to cutthroat competition, the leadership in commercial deals has shifted from suppliers to buyers. Consequently, the suppliers' appropriate response to buyers' and customers' demands becomes one of the primary means to achieve a competitive advantage. Hence, in order to respond to the power wielded by customers (buyers and end-users), the suppliers need to customize their products and services according to the customers' tastes and desires to cater to the likes of each customer.

It is necessary to (1) move the managerial point from the conventional vertical communication system usually found in organizations to a horizontal communication system and (2) establish a Business Process Management (BPM) system that can speedily and flexibly manage its responses to such environmental changes. This paper will discuss a framework that incorporates the understanding, construction, management, and evaluation 
of the business process both inside and outside the corporation such that the customers are satisfied in the competitive environment in the IT era.

\section{Necessity and Possibility of Process Management in the IT Era}

We live in a fast-paced world where things are constantly changing; therefore, it is increasingly difficult to predict what will happen in the near future. Moreover, the development of information that allows one to circumnavigate the limits of time and space on global business transactions has been altering the corporate environment in various ways. This environmental change necessitates that companies swiftly match the input of environmental changes with corporate output. In particular, because of the traditional response which focuses on functions often results in an accumulation of information and materials due to the imbalance among functions and the barriers among the many functions, there is a need for a swift response to the environmental changes from the process management perspective. In the IT era, the necessity of and possibilities for process management are being propounded simultaneously by the following two demands (Monden et al., 2007, pp. 235-248).

\subsection{Demand from the management side}

The leadership in commercial deals has shifted from vendors to customers due to the easy access to the Internet and cutthroat competition, and hence, a company needs to plan and offer its products or services in line with the customers' views. In other words, there is a need for horizontal organization management that considers the customer as the starting point.

Meanwhile, triggered by the window dressing settlement of Enron and WorldCom, the Corporate Reform Act (Sarbanes-Oxley Act: the SOX act) was executed for its recurrence prevention in the US. This act imposes a duty of the construction and accountability of internal control to which a manager guarantees the reliability of financial statements. In this act, the same duty is also imposed on both the US and the non-US companies. This strengthening of the supervisor function of managers or inspectorial agencies to such internal control requires a business process to be managed and documented appropriately. The aim of this law was to improve 
the reliability of financial statements by clarifying a business process; however, it is understood that, at the same time, a business process must be built to guarantee competitive advantage. Therefore, following changes in a company's environment, such as a surge of customer power, there is an increase in expectation from process management as well as in legal demands for the preparation and application of internal control.

These demands from the management side can be attained by a system that integrates material flow and information flow. Therefore, the construction of a BPM system that can manage the performance of the business process based on the customer's view is deemed most valuable as an important means to cater to the demands from the management side.

\subsection{Support from innovation in IT}

In the 1990s, Business Process Reengineering (BPR) approaches that tried to achieve a drastic restructuring of the business process using IT failed because they were unable to obtain the expected support from IT. In the latter half of the 1990s, information management using Enterprise Resource Planning (ERP) originated as a result of the failure of these BPR approaches. However, ERP confined the operations into a concrete box, which was unable to support the changing operation flow. Hence, in the 2000s, (1) Service Oriented Architecture (SOA) technology that has enabled the restructuring of the IT environment to allow it to respond more flexibly to the environmental changes and (2) various softwares (Harmon, 2010, pp. 75-77) that have enabled the support of the changing operation flow flexibly have been developed. These are effective tools for the construction of BPM system because these new abilities can be exercised to create the business process and assess real-time performance management virtually.

\section{History of BPM}

In today's IT era, information is treated on a global scale, the power of information spreads around all areas, and information control has become a means of producing competitive advantage. Moreover, in the global competitive environment, past experiences of success lose their worthiness, and management must always monitor changes in the environment, respond 
speedily, and obtain the outcome with certainty. However, organizational goals and management resources are distributed using a top-down approach based on the vertical organization. As a result, a mismatch frequently arises in the supply and consumption of resources due to the partition between the function and the department. This becomes an obstacle to achieving the expected goal. Therefore, establishment of a new management technique from the resource-consumption point of view is required.

However, according to the results of the Internet questionnaire targeting the readers of a Web magazine (Business Process Trends) in 2006 for the purpose of investigating the company trend, BPM was not recognized as a broadly accepted fixed model, as shown in Fig. 1; in other words, BPM has not managed to become more than just a way to share information within the organization by IT and to support decision making. Nevertheless, some companies have been able to manage the process using BPM to a considerable extent. Moreover, through IT innovation, it is becoming possible to build and manage BPM at low cost.

As long as the term "BPM" refers to the management of the business process of horizontal organization, we can say that the origin of process management dates back to the Tailorist approaches. On the other hand, it is said that the trigger that led to the recognition of BPM in Europe and the US was the Total Quality Management (TQM) approach adopted in the 1980s (Jeston \& Nelis, 2006, pp. xii-Xvi). In the 1990s, European and American companies faced a stagnant market and cutthroat competition across the globe. This led to further development of the ideas of traditional

\begin{tabular}{|lcr|}
\hline Which of the following best describes-what BPM means to you? & Number & Ratio (\%) \\
\hline $\begin{array}{l}\text { 1. An approach to process redesign or improvement } \\
\text { 2. A cost-saving initiative focused on increasing productivity }\end{array}$ & 21 & 18 \\
$\begin{array}{l}\text { 3. A set of software technologies for automating and managing runtime } \\
\text { business processes }\end{array}$ & 79 & 6 \\
$\begin{array}{l}\text { 4. A management philosophy that focuses on organizing } \\
\text { the business around its business processes }\end{array}$ & $\mathbf{1 8 7}$ & $\mathbf{5 4}$ \\
\hline \multicolumn{1}{|c|}{ Total } & 348 & 100 \\
\hline
\end{tabular}

Fig. 1. Survey results on the meaning of BPM submitted by the management over the world Source: Celia \& Harmon (2007). 
process management, and new methods such as BPR and Six Sigma emerged. BPR was suggested by Hammar in 1990. His article "Don't automate, obliterate" in the Harvard Business Review (1990) was the starting point from which BPR disseminated quickly. Although BPR aimed to drastically restructure the business process using IT, IT was unable to describe and support the complicated processes (Jeston \& Nelis, 2006, pp. xii-xvi).

Drawing upon the lessons learned from the failure of BPR, ERP was introduced in the latter half of the 1990s. It appeared as though ERP had already solved the process management problem related to IT; however, ERP was unable to support process improvement because it suffered from many shortcomings including non-flexibility, despite the fact that it was sold with the catchphrase "best practice". In other words, after ERP was set up, the flexibility of the process was lost and could be likened to dry concrete, even though initially (before installation), ERP was as flexible as wet cement (Smith \& Finger, 2007, p. 73).

There are two opinions regarding the origin of BPM. One is that it originated in the 1990s (Jeston \& Nelis 2006, pp. xii-xvi) and the other is that it emerged after the year 2000 (Jeston \& Nelis, 2006; Smith \& Finger, 2007). However, it seems that the difference between these two opinions arises from (1) the time frame of the emergence of IT that supports process management and (2) the history of process management. The latter viewpoint emphasizes IT innovation that supplements the lack of flexibility in ERP. This viewpoint treats BPM according to the development of the Business Process Management System (BPMS), i.e., as a total management system of business process that supports a flexible unity between business process and IT. However, a consensus regarding the content of BPM is yet to be reached and BPM has been reduced to a three-letter acronym used to refer to process management.

Harmon (2010, pp. 37-38) showed that there are three streams in the methodology for the management of a business process. These are streams of management, Quality Control (QC) and IT. Each stream has mutually ignored the other streams or degraded their worthiness until now. However, Harmon stated that the three streams have now been included in comprehensive BPM. 


\section{The Concept of Process}

A process is a series of interlinked activities that achieve a specific objective (Daly \& Freeman, 1997, p. 16). Davenport (1993, p. 5), however, defines the process as follows: "A process is simply a structured, measurable set of activities designed to produce a specified output for a particular customer or market". Therefore, we can say that the definition of process differs with each person. This is the reason why each writer defines the process differently on the basis of the measurement unit, categorization, and extent of the process.

This paper regards the process as "a flow composed of various mutually dependent groups of activities toward the creation of customer value, the input and the output of which are clearly distinguished, and which have a hierarchical structure depending on the levels of the subject matters of management". In addition, it is desirable for the process to satisfy the following three key elements as explained in Statements on Management Accounting (SMA) No.4NN (2000, p. 8).

Transformation: By means of one or more changes, it provides output from a group of interrelated work activities that is of greater value than the inputs.

Feedback control: Involves some regulatory means by which the transformation activities are modified or collected to maintain certain attributes of the output.

Repeatability: Implies that a process is executed many times in the same manner.

\section{Process Classification Framework (PCF) of the American Productivity \& Quality Center (APQC)}

Supply-chain operations reference (SCOR) of the Supply Chain Council (SCC) is a well-known business process framework. SCOR is composed of three levels. SCC formulates the process framework until level 3, and the individual firm builds level 4 based on the condition of its company. In addition to SCOR, other frameworks include the Value Reference Model (VRM) built by the Value Chain Group, eTOM developed for 
a telecom company, and the APQC framework that incorporates the base elements of SCOR (Harmon, 2010, pp. 61-63).

In particular, the free benchmarking service SCORmark, which is provided for SCC members and operated by SCC, APQC, and IBM together, is an available reference model for BPM construction. However, Harmon (2010, pp. 72-74) pointed out that as some companies are building various simple to very complex processes, the above-mentioned standardized processes can only be used as reference models. In addition, because the management of complex processes is difficult, companies are required to clarify the management purpose of the processes.

\title{
6. Process Management Unit and Operation Flow
}

In process management, the process initiated by the event will be described as a management unit on the basis of the partitions of the connected function and activity. In other words, it is necessary to solve the issue of how to describe and define the process as a management unit. The process management unit is an inter-departmental specific process wherein the output is repeatedly delivered from the flow of activities connected to two or more departments. The event is the occurrence that starts the process. Therefore, the event differs from the function that uses time. Further, as shown in Fig. 2, the event is related to a point in time. The process controls the functions in the sense that it is the process that uses a function or the connected functions as a set of activities (Seidelmeier, 2004, pp. 70-71).

Davenport (1993, p. 28) explains the basis for the decision about the length of the process as follows:

\begin{abstract}
The objective of process identification is the key to making these definitions and determining their implications. If the objective is incremental improvement, it is sufficient to work with many narrowly defined processes, as the risk of failure is relatively low. But when the objective is radical process change, a process must be defined as broadly as possible.
\end{abstract}

Davenport (1993, p. 31) also adds that process definition is more of an art than science. 


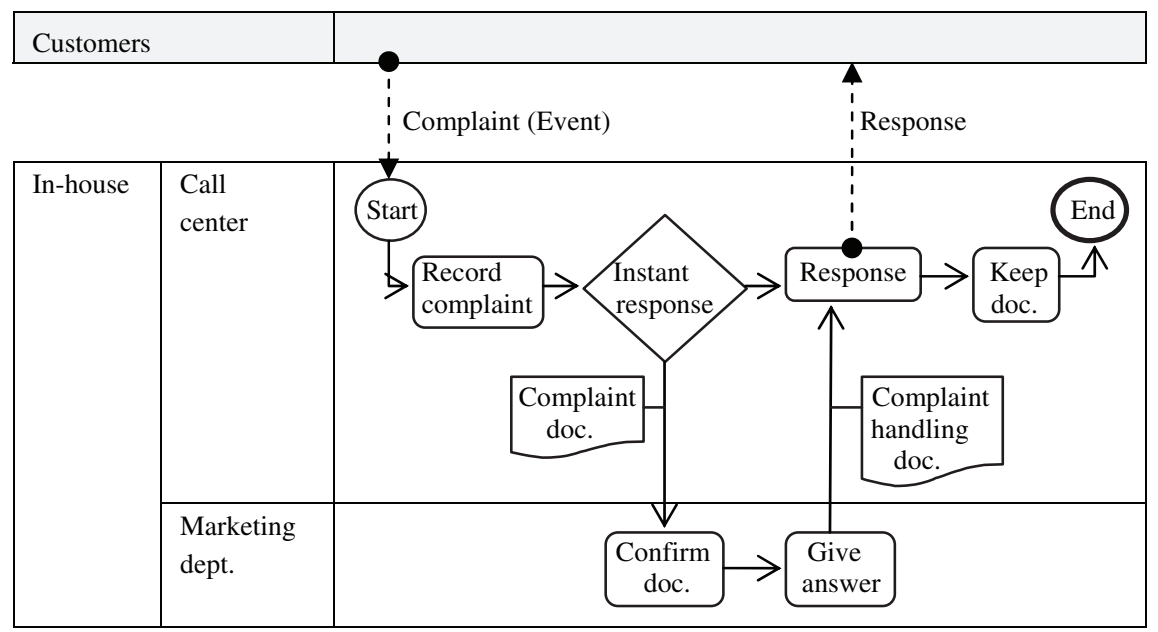

Fig. 2. Example of a trouble-shooting process

Source: Takeyasu et al. (2007, p. 3); modified by author.

Meanwhile, the Software Engineering Institute (SEI) of the Carnegie Mellon University developed the Capability Maturity Model Integrated (CMMI) in 1987 to systematically evaluate the construction and control level of a process, as shown in the Fig. 3. CMMI is a criterion of judgment that diverts the developed method in order to evaluate the development level of the software and identifies the standardized process level that matches with the actual operation level. That is, even if the company has a business process model, the control levels of a process will differ depending on which level the process construction is progressing.

On the other hand, it is relatively easy to construct a barometer that estimates whether a specific process is working efficiently. However, it is difficult to estimate whether the given process contributes to the outcome of a company. Therefore, a method that systemically connects a business goal and a process target is necessary, and a Balanced Scorecard (BSC) can be used in this matter. However, a traditional BSC focuses on the performance measure of a function or department rather than the process itself. In the field of process valuation research, application of a BSC that links a department performance measure and a process performance 
Level 5: Processes Continuously Improved

Processes teams continuously

improve processes

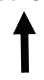

Level 4: Processes Are Managed

Processes are measured and managed systematically

Level 3: Most Processes Organized

Management processes are organized and improved at the enterprise level

Level 2: Some Processes Organized

Management processes are improved at the work group level

Level 1: No Processes Organized (Cultures of Heros)

Fig. 3. The CMM model with five levels of maturity

Source: http://www.bptrends.com/publicationfiles/spotlight_051909.pdf.

measure is gaining attention recently (Harmon, 2010, pp. 66-67). In the conventional result-oriented approach, operating performance is measured and evaluated using the following steps (Castellano et al., 2004):

(1) Assign a performance target to the applicant (department).

(2) Combine the realization value of a target and a key performance indicator.

(3) Measure the realized value against the target for every fixed period.

(4) Reward.

However, this approach possesses the following disadvantages:

(1) Generally, a targeted value is fixed arbitrarily.

(2) A targeted value does not consider the actual result or capacity of the present process.

(3) It does not consider the correlation within the processes in a goalsetting process.

(4) It does not understand the connection between the realized performance value and performing-a-task method.

Moreover, Kittredge (2004) stated that one main reason why the roles of management accounting and process management differ is that the 
viewpoint of a measurement barometer is not in harmony. In a BSC, the strategic goal is deployed up to the performance-evaluating indicators of operations. However, the perceptions of the manager or the process manager concerning the performance measurements are different when the measurement criterion of the operations is not linked with the strategy or when the criterion is not integrated through the management units of the function and the process, and so forth. As a result, it is easy to execute a strategy that is not accepted by the workers in the field. Kittredge (2004) insists that such problems can be solved if the performance indicators conform to the measurement indicators of the strategically and tactically important processes chosen by the process managers are reflected in the $\mathrm{BSC}$ and these indicators are deployed on the BSC.

\section{Structure of BPM}

BPM is "the control and management of transactions between organizations both inside and outside corporations by viewing the transaction flows as processes, which is enabled by breaking up the traditional walls between organizations, sharing information and resources among them, and combining and connecting their transactions" (Lee et al. 2009). To sum up, BPM has the following features:

(1) Evaluate the process as a management unit.

(2) Focus on the consumption of resources of a horizontal organization instead of on the supply of resources of a vertical organization.

(3) Visualize a process with IT support.

(4) Perform visualized control by sharing process information within the organization.

(5) Promote performance improvement by using process information from the perspective of cost/time/capacity.

This paper divides BPM into two: a process chain management inside the corporation that surpasses the functional and departmental barriers and a process net strategy outside the corporation that surpasses the barriers among corporations. 


\subsection{Process chain management}

In an organization that focuses on functions, the business operation is managed because of the function, and managers naturally consume and manage resources according to the functional budget and emphasize the strict adaptation of standards. Consequently, because employees are eager to observe the functional standards and save resources, the relationships among business process, suppliers, and customers are not optimized (Department of Defense, 1994). Gradually, there emerges an expectation that process chain management will remove the barriers among the functions as shown in Fig. 4 to optimize the whole value chain by completing link A and integrate the main process with the support process by completing link B. IT innovation enhances the possibility of this action. On the other hand, it is said that in today's competitive environment, a large company does not defeat a smaller one, but a fast company defeats a slower one.

However, under the uncertain environment that cannot correspond at a speed alone, there is a demand for a process management system that can manage the process promptly and flexibly according to the changes in the market environment. For such a process management system, it is necessary to achieve a balance between the value chain (to manage the process in a horizontal organization) and management chain (to manage the horizontal organization using the Plan-DoCheck-Action (PDCA) cycle).

In other words, the process PDCA cycle rather than the departmental PDCA cycle that occurs within the department is preferable for the systematic, integrated, continuous improvement of the whole process; this is

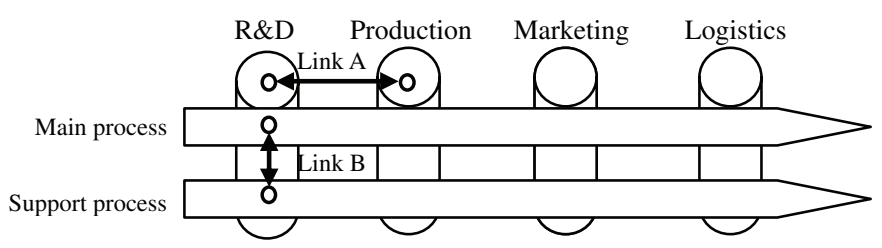

Fig. 4. Value-chain optimization of business process 


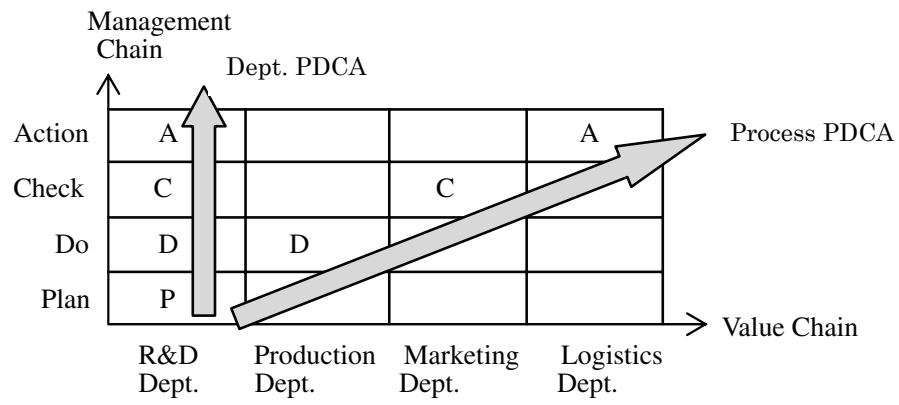

Dept: department

Fig. 5. Value chain and process PDCA

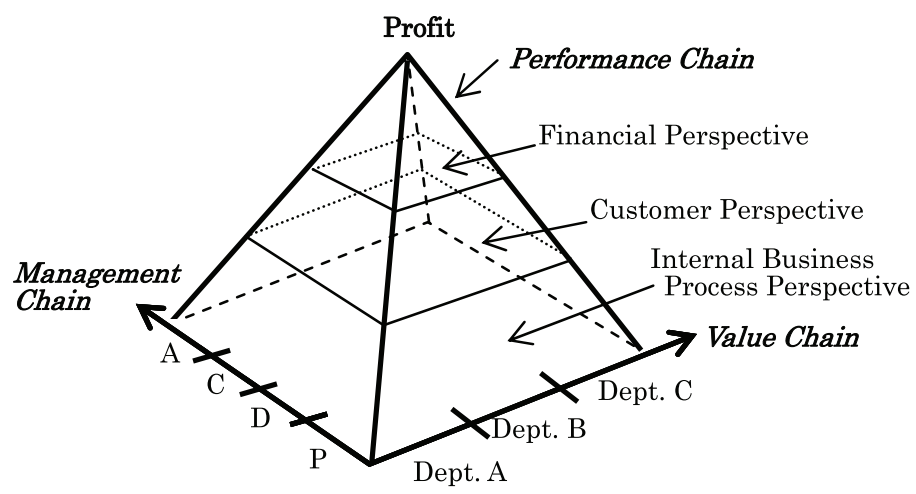

Fig. 6. Integration of the three chains

shown in Fig. 5. That is, the management system is expected to perform the process PDCA cycle for all the processes across all departments. As a result, process management aims for optimal harmony between the value chain of business processes and the management chain, which allows us to overcome the traditional walls between organizations and carry out the management cycle of the organization's management. However, in order to connect the outcome of process management to financial performance through a performance chain, the operating performance of a process must be measured (see Fig. 6).

In BSC, the lead indicators are the performance drivers and lag indicators are the outcomes. The lag indicator only identifies the present position 
and illustrates the change in the indicator. However, the lead indicator identifies the destination and requires an early decision. Therefore, we can say that the lead indicator is preferable in process management when it comes to the real-time management of the performance.

In general, the effect of the change in the process on the consumption of resources in the process can be easily identified; however, estimating the reverse is not that easy. If performance management and process management harmonize in the manner mentioned above, the process can be managed by using the performance chain as shown in Fig. 6. In other words, important performance drivers that yield the desired outcome in BSC can be systemically linked with the strategic goal if they are chosen from each of the process outputs. In addition, in $\mathrm{BSC}$, we can also determine the direction of the process management. As a result, at the process level, the targets determined using a top-down approach match the management indicators chosen using the bottom-up approach, and the application of PDCA cycle on BSC becomes possible, such that an integrated management system, as depicted in Fig. 6, can be constructed.

\subsection{Process net strategy}

The competitive environment has already shifted from competition among companies to competition among process networks that aim to construct a syndicate. In such an environment, the selection, concentration, and collaboration strategies of the process, such as inter-firm process-level alliances, shared services, and outsourcing part of the business process, are adopted because of the expectation that these steps will yield competitive advantage. It is said that the strategic process net construction can be divided into the four following strategies (Yamada \& Uchida, 1999):

(1) Choose and manage only the function that becomes the key of the competitive advantage within the existing value chain and outsource with the rest to realize lower costs.

(2) Aim toward creating an oligopoly in particular processes by focusing on special processes within the existing value chain that add significant value and supplying the same to multiple companies. 
(3) Streamline the value chain by cutting the unnecessary processes and focus on customer satisfaction.

(4) Add value by adding new functions when the customers' needs exceed the capability of the existing value chain.

In other words, the process net strategy is a decision-making approach whereby the processes are selected and concentrated on the basis of the corporate strategy as well as considering the plausible changes in the environment. This approach is adopted both inside and outside the company/country.

Using a strategy that secures the functional advantage in the value chain under a competitive environment, the company is confronted with a decision-making problem - of whether to buy the functional advantage or develop it. In general, in an industry where environmental changes are not that intense, it is preferable for the company to choose the strategy of developing the functional advantage so as to always sustain the mainspring of long-term growth. However, when long-term growth is somewhat elusive, this strategy has a negative effect in that it increases costs. Consequently, the strategy of buying the functional advantage needs to be constructed by the collaboration of the business process such as the selection, the concentration, and the collaboration of the business process.

\subsubsection{Business process collaboration}

In today's competitive environment, which is characterized by increasing uncertainty and severity, it is necessary to decrease the risk generated by environmental changes and adopt strategic means to maintain and expand one's competitive advantage. In other words, it is necessary to invest limited managerial resources to identify and foster a process that may become a core competence and to utilize resources outside the corporation, if necessary, for processes other than core competence. This approach is deemed feasible because using other corporations' assets, rather than creating or buying new assets necessary to respond to environmental changes, can decrease the economic risk and also because this improves corporate flexibility and enables the company to respond to environmental changes in a short amount of time (Hagel, 2003). 


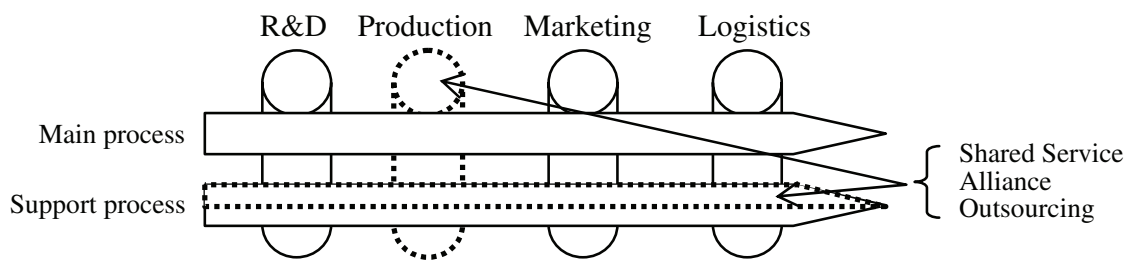

Fig. 7. Business process collaboration

However, this approach does necessitate that an intra-corporate process network that smoothly connects processes across multiple corporations and that exchanges real-time information regarding the same is built. As this problem is, to a great extent, solvable using the Internet, and in particular, the Web services architecture, such as business process networks are possible. Therefore, in the information era, it is said that the company that shares information attains more success than the company that manages information. Fig. 7 depicts a case wherein the product is procured from an Electronics Manufacturing Services (EMS) company, i.e., outsourcing, and the data processing is delegated to a special company, i.e., shared service.

\subsubsection{Patterns of business process collaboration}

In this paper, alliance, outsourcing, and shared service, etc. are considered as the main examples of business process collaboration. However, it is not easy to define business process collaboration because the above-mentioned features and their ranges can be changed. Therefore, the paper proposes that the collaboration is considered to have taken place when the company performs the following activities in the business process network across companies.

Outsourcing: Some particular processes except the processes that the company performs are delegated to another company (or other companies).

Shared service: Similar processes that the companies perform are concentrated together.

Alliance: $\quad$ Some processes that the company performs are supplemented by the cooperating company. 
In the IT industry, the system of cheaply procuring components from third parties and assembling them in-house is being generalized. The company with the horizontal-division-of-labor type business structure is the case. However, there also exist companies that have adopted a reverse strategy and have extended their profits. There are cases of companies with the vertical-division-of-labor type business structures. If we selected the case of liquid crystal TV, Sony of Japan has a horizontal-division-oflabor type and Samsung of South Korea has a vertical-division-of-labor type structure. If panels of liquid crystal TVs can be procured from outside companies at low price, there will be no need for insourcing the panel through vertical integration. The vertical integration type, which involves intentional investment and in-house production, becomes less beneficial, and the horizontal-division-of-labor model becomes dominant instead. However, Samsung produces the panel in-house with a vertical integration type and is still gaining profits. This is because they have an absolute sales amount that can cover both fixed and variable costs (Nikkei Business, 2011). Depending on how the company responds to the current circumstances, it will use the vertical-division-of-labor type strategy of taking an investment risk or the horizontal-division-of-labor type strategy of responding to the risk of demand fluctuation.

\section{Conclusion}

While many new process management techniques have been proposed recently, BPM is the general term used to refer to these. However, process-oriented management is not a new concept in business management; in fact, process-oriented management was simply not feasible until now. Today, cooperation and integration among business processes, which hitherto were impossible, have become possible because data processing and telecommunication have evolved a great deal due to advancements in IT. On the other hand, process management is also required to effectively respond to the changes in the highly competitive environment not only with respect to customer satisfaction but also with time, flexibility, and cost.

Though many companies have attempted process restructuring (e.g., BPR), few have achieved their objectives. It seems that this might be the 
case because these companies did not establish a process management mechanism to improve the efficiency of the entire process and ensure the stability of the reformed processes, which are the problems of BPR that were mentioned in this paper. Hence, while many new process management techniques to overcome such problems are being proposed today, it is not easy to create a systematical method of process management to improve the efficiency and stability of the restructured process. In the current environment, where the changes are intense and unforeseeable and any past success or experience has lost its meaning, BPM, which allows the synchronization of the company's output with the changes in the environment, will be an effectual tool to obtain competitive advantage.

\section{References}

Castellano, J. F., Young, S., Anderson, D. \& McLean, W. (2004). Process-based Measurements: The Key to more Effective Decision Making, Cost Management, pp. 5-14.

Celia, W. \& Harmon, P. (2007). Business Process Management and Service Oriented Architecture. http://www.bptrends.com/bptrends-surveys/.

Daly, C. \& Freeman, T. (1997). The Road of to Excellence: Becoming a ProcessBased Company (The CAM-I Process Management Guide), Institute of Management Accountants, CAM-I.

Davenport, T. H. (1993). Process Innovation - Reengineering Work Through Information Technology, Harvard Business School Press.

Department of Defense. (1994). www.c3i.osd.mil/bpr/bprcd/mhome.htm.

Hagel, III. J. (2002). Leveraged Growth: Expanding Sales Without Sacrificing Profits, Diamond Harvard Business Review, pp. 68-77.

Hammer, M. \& Champy, J. (1990). Reengineering Work: Don't Automate, Obliterate, Harvard Business Review, pp. 104-112.

Harmon, P. (2010). The Scope and Evolution of Business Process Management, Handbook on Business Process Management I, J. V. Brocke and M. Rosemann (eds.), Springer.

Jeston, J. \& Nelis, J. (2006). Business Process Management - Practical Guidelines to Successful Implementations, Elsevier.

Kittredge, J. (2004). Process Management and Cost Management: Collaboration or Opposition, Cost Management, pp. 23-30. 
Lee, G., Kosuga, M. \& Nagasaka, Y. (2009). The Usefulness of Business Process Management in Cost Management, The Journal of Cost Accounting Research, Japan Cost Accounting Association, Vol. 33, No. 1, pp. 18-27 (in Japanese).

Monden, Y., Kosuga, M., Nagasaka, Y., Hiraoka, S. \& Hoshi, N. (2007). Japanese Management Accounting Today, World Scientific.

Nikkei Business (January 31, 2011). Television War not to be Tomorrow Samsung, the Facts of Turn to Red Figures, pp. 21-34, (in Japanese).

Seidelmeier, H. (2004). Business Process Modeling by ARIS, BNN (in Japanese). Smith, H. \& Finger, P. (2007). Business Process Management: The Third Wave, Meghan-Kiffer Press.

Statements on Management Accounting No.4NN. (2000). Implementing Process Management for Improving Products and Services, Institute of Management Accountants.

Takeyasu, K., Miyazaki, Y. \& Higuchi, Y. (2007). The Recording Method of Work Flow for Internal Control, Chuokeizaisya (in Japanese).

Yamada, H. \& Uchida, K. (May 10, 1999). Creative Destruction of Value Chain, Nihon Keizai Shinbun (in Japanese). 